\title{
MANOMETRIC STUDIES OF THE PRESSURE-VOLUME RELATIONSHIP IN LIVING AND ENUCLEATED EYES OF INDIVIDUAL HUMAN SUBJECTS*†
}

\author{
BY \\ JOHN E. EISENLOHR, M. E. LANGHAM, AND A. E. MAUMENEE \\ From the Wilmer Institute, Johns Hopkins University Medical School, Baltimore, Maryland
}

IN a previous investigation a significant difference was found in the pressure response of the living and dead eyes of individual rabbits when a given volume of fluid was injected into the eye (Eisenlohr and Langham, 1962). An increase in the intra-ocular pressure of living animals was found to force blood from the eye and the amount lost per unit pressure increase was found to reach a maximum as the pressure approached the arterial blood pressure. The observations were made by recording manometrically the response of the intra-ocular pressure either to a sudden injection of a predetermined volume of fluid given in ascending and descending pressure steps or to a continuous infusion of saline at a rate greatly exceeding the outflow of aqueous humour. The latter method gave a continuous function of the pressure response of the eye and had the merit that observations over a wide range of pressures could be completed within 10 to 15 seconds. It is the purpose of this study to apply these techniques to the living and freshly enucleated eyes of individual subjects to determine whether vascular changes within the human eye significantly modify its pressure-volume relationship.

Since this work was begun, Ytteborg $(1960 \mathrm{a}, \mathrm{b})$ has investigated this problem in a somewhat different manner. The results and conclusions to be reported in this paper agree in some but not in all respects with those of Ytteborg, and the reasons for the differences are discussed.

\section{Method}

Of the six eyes available for study $\ddagger$, five were enucleated because of choroidal melanomata and one normal eye was removed in the course of an orbital exenteration. The anterior segment of each eye was normal to slit-lamp examination and none of the eyes was glaucomatous. Except for one eye examined under Xylocaine retrobulbar anaesthesia, all studies were carried out with the patients asleep. Non-explosive general anaesthetic agents were employed so that unshielded electronic recording instruments could be brought into the operating room.

\footnotetext{
* Received for publication November 24, 1961.

† This work was supported in part by Special Fellowship BT-627, National Institutes of Health to J. E. Eisenlohr and by Research Grant B-2591, National Institutes of Health, Bethesda, Maryland.

$\ddagger$ We wish to thank Drs. Wm. Newby, C. E. Iliff, and R. Day for kindly making three of the patients reported in this study available to us.
} 
After the patient was anaesthetized a 23 -gauge needle attached to 50 polyethylene tubing was passed into the anterior chamber at the temporal limbus. This cannula was in turn attached to a lucite block fitted with self-contained taps as previously described by Langham (1959). To this same block were also attached a saline reservoir, the pressure transducer, and the infusion apparatus. The use of this block made infusion into the eye and pressure recordings possible through one needle only. Preliminary studies on rabbits had confirmed the accuracy of pressures recorded in this manner (Eisenlohr and Langham, 1962). By means of the saline reservoir, the intra-ocular pressure could be established at any level before an infusion.

The infusion of saline was of two types, rapid and continuous. For the rapid technique an Agla micrometer syringe fitted with a mechanical "stop" was used, permitting predetermined amounts of normal saline (about $10 \mu \mathrm{l}$ ) to be injected into the eye with one rapid twist of the micrometer screw. The accuracy of the syringe was determined independently and found to be within \pm 0.5 per cent. of the manufacturer's stated calibration. The plunger of the syringe was lubricated with silicone stopcock grease to prevent leakage. For continuous infusions the device previously described by Langham (1959) was fitted with a 5-ml. syringe coated internally with silicone grease. The machine with this syringe was calibrated and found to deliver at its maximum rate $197 \mu 1 . \mathrm{min}^{-1}$.

Pressure measurements and recording were made by means of a Sanborn 267B pressure transducer, 150-1100 AS carrier pre-amplifier, and 154-100B direct writing pen-recorder. Before an experiment the entire apparatus was cleaned and, except in two cases, sterilized in either $\beta$-propriolactone or ethylene oxide. It was assembled in the operating room, filled with boiled physiological saline, and examined for leaks and trapped air bubbles. The recording system was balanced and calibrated to give a deflection of $1 \mathrm{~mm}$. mm. $\mathrm{Hg}^{-1}$ for the continuous and 2 $\mathrm{mm} . \mathrm{mm} . \mathrm{Hg}^{-1}$ for the rapid method of infusion.

Because a small volume of saline was required to raise the pressure in the polyethylene tubing and the transducer, this volume had to be subtracted from the total amount injected to obtain the net volume of saline entering the eye. The correction was found to be linear with respect to pressure and to have an average value of $0.021 \mu 1 . \mathrm{mm}^{\prime} \mathrm{Hg}^{-1}$ (range .005 to $.065 \mu 1 . \mathrm{mm} . \mathrm{Hg}^{-1}$ ) for the rapid, and a mean value of $0.023 \mu \mathrm{l} . \mathrm{mm} \mathrm{Hg}^{-1}$ (range .015 to $.040 \mu \mathrm{l} . \mathrm{mm}$. $\mathrm{Hg}^{-1}$ ) for the continuous technique. In addition, a correction had to be applied in the case of the continuous infusions for the volume of aqueous lost through the usual outflow channels during the 15 to 20 seconds required for an infusion. This was done by using the values for ocular rigidity calculated from the rapid injections to analyse individual pressure decay curves in the living and the enucleated eyes in steps of 10 $\mathrm{mm}$. $\mathrm{Hg}$ as described by Grant and Trotter (1955). At its maximum the outflow correction derived in this fashion was 18 per cent. of the total volume infused, but for most pressure ranges was considerably less than this. Alternatively, the facility of outflow was calculated for each eye separately from pre-operative applanation and tonographic data as described by Moses and Becker (1958). Assuming this facility of outflow to remain constant with increasing pressure, an outflow correction was determined which altered the calculated values for ocular rigidity less than 10 per cent. 
The resistance to flow offered by the cannula was largely responsible for a pressure overshoot which obscured the earliest portion of the rapid infusion records (Eisenlohr and Langham, 1962). To obtain a measure of what the intraocular pressure would have been if equilibration throughout the eye and infusion system had been instantaneous, the slope of the pressure decay curve one second after the injection was extrapolated back to zero time. The resistance to flow with a 23-gauge needle also resulted in a constant $2 \mathrm{~mm}$. $\mathrm{Hg}$ pressure gradient between the plastic block and the eye during the continuous infusion of $197 \mu \mathrm{l} . \mathrm{min} .^{-1}$ of saline. While this gradient could be abolished by the use of larger cannulas, it was considered desirable to disturb the living eye as little as possible. Thus all infusions in vivo were made through 23-gauge needles, and a $2 \mathrm{~mm} . \mathrm{Hg}$ adjustment was made in the continuous infusion records.

The technique of making individual measurements was the same for both the living and the enucleated eyes. All taps in the plastic block were opened and the intra-ocular pressure brought to the desired level by means of the saline reservoir. The tap to the reservoir was then closed and either the rapid or the continuous infusion was started at once. In the case of the rapid injections, the lowest pressure levels were studied first and the intra-ocular pressure was increased stepwise in increments of 10 to a maximum of $55 \mathrm{~mm}$. Hg. Starting at $50 \mathrm{~mm} . \mathrm{Hg}$, the measurements were continued as the initial intra-ocular pressure was lowered in steps of $10 \mathrm{~mm}$. Hg. Thus the entire range from 15 to $55 \mathrm{~mm}$. Hg was covered in steps of $5 \mathrm{~mm}$. Hg. Ordinarily at least three injections were made at each pressure level and the values reported represent the arithmetic mean of these determinations. In the case of the continuous records, the intra-ocular pressure was brought to $15 \mathrm{~mm}$. $\mathrm{Hg}$ and a series of three or more continuous saline infusions was made covering a range of pressure similar to that of the rapid technique. The values reported for ocular rigidity from a given eye are mean values from all the continuous recordings done on that eye.

The measurements on the living eye required about 30 minutes. Immediately after enucleation, the globe was supported in saline-moistened cotton and all studies were repeated. The rapid technique was used with all six eyes before and after enucleation, and the continuous method with three patients. For the first two eyes studied, the cannula was left in place as the globe was removed. However, the anterior lens capsule of the second eye was inadvertently ruptured by the cannula during surgery, so for the remainder of the studies the needle was withdrawn after completing the initial measurements. The enucleated globe was recannulated through the original puncture site with a needle of larger diameter than that originally used in order to prevent leakage.

\section{Results}

Tables I and II (opposite) summarize the clinical, tonometric, and tonographic measurements made on patients whose eyes were used in this study.

The effect on the intra-ocular pressure of an infusion of $197 \mu 1$ min. $^{-1}$ saline into the anterior chamber of a human eye before and immediately after enucleation is shown in Fig. 1 (opposite). The observations could be reproduced accurately in any given eye and are typical of all the eyes examined. 
TABLE I

SUMMARY OF CLINICAL FINDINGS IN SIX PATIENTS USED IN THIS STUDY

\begin{tabular}{|c|c|c|c|}
\hline Case No. & $\begin{array}{l}\text { Age } \\
\text { (yrs) }\end{array}$ & Sex & Pathology \\
\hline 1 & 57 & F. & $\begin{array}{l}\text { Malignant melanoma of the choroid, spindle cell } \\
\text { type } A \text { and } B \text {, measuring } 5 \times 3 \times 2 \mathrm{~mm} \text {. }\end{array}$ \\
\hline 2 & 39 & F. & $\begin{array}{l}\text { Malignant melanoma of the choroid, spindle cell } \\
\text { type A and B, measuring } 5 \times 4 \times 2 \mathrm{~mm} \text {. }\end{array}$ \\
\hline 3 & 57 & M. & $\begin{array}{l}\text { Malignant melanoma of the choroid, mixed cell } \\
\text { type, measuring } 7 \times 7 \times 5 \mathrm{~mm} \text {. }\end{array}$ \\
\hline 4 & 66 & M. & Normal eye \\
\hline 5 & 46 & M. & $\begin{array}{l}\text { Malignant melanoma of the choroid, spindle cell } \\
\text { type } A \text { and } B \text {, measuring } 6 \times 0 \times 0 \mathrm{~mm} \text {. }\end{array}$ \\
\hline 6 & 57 & M. & $\begin{array}{l}\text { Malignant melanoma of the choroid, spindle cell } \\
\text { type A. }\end{array}$ \\
\hline
\end{tabular}

TABLE II

RESULTS OF PRE-OPERATIVE STUDIES IN FIVE PATIENTS.

The case numbers correspond to those in Table I. The eye studied is indicated in the first column.

\begin{tabular}{|c|c|c|c|c|c|c|c|}
\hline \multirow{3}{*}{ Case No. } & \multirow{3}{*}{$\begin{array}{c}\text { Eye } \\
\text { Studied }\end{array}$} & \multicolumn{4}{|c|}{ Intra-ocular Pressure (mm. $\mathbf{H g})$} & \multirow{2}{*}{\multicolumn{2}{|c|}{$\begin{array}{l}\text { Coefficient of Outflow } \\
\left(\mu \mathrm{l} . \mathrm{min} .^{-1} \mathrm{~mm} . \mathrm{Hg}^{-1}\right)\end{array}$}} \\
\hline & & \multicolumn{2}{|c|}{ Applanation } & \multicolumn{2}{|c|}{ Schiötz } & & \\
\hline & & Right & Left & Right & Left & Right & Left \\
\hline $\begin{array}{l}1 \\
2 \\
3 \\
4 \\
6\end{array}$ & $\begin{array}{l}\text { Left } \\
\text { Left } \\
\text { Left } \\
\text { Right } \\
\text { Right }\end{array}$ & $\begin{array}{c}14.0 \\
13.0 \\
15.0 \\
16.0 \\
-\end{array}$ & $\begin{array}{c}13.0 \\
14.0 \\
15.0 \\
19 \cdot 0 \\
-\end{array}$ & $\begin{array}{l}12 \cdot 2 \\
11 \cdot 4 \\
15 \cdot 2 \\
18 \cdot 2 \\
17 \cdot 3\end{array}$ & $\begin{array}{l}11 \cdot 2 \\
12 \cdot 4 \\
10 \cdot 6 \\
17 \cdot 4 \\
17 \cdot 3\end{array}$ & $\begin{array}{c}0.29 \\
0.27 \\
0.46 \\
0.26 \\
-\end{array}$ & $\begin{array}{c}\mathbf{0} \cdot 33 \\
\mathbf{0} \cdot 17 \\
\mathbf{0} \cdot 29 \\
\mathbf{0 . 4 3} \\
-\end{array}$ \\
\hline
\end{tabular}

LIVING EYE

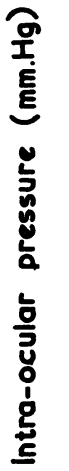

ENUCLEATED EYE

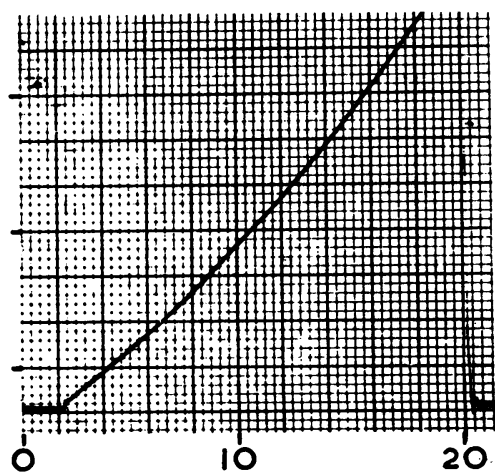
TIME (sec.)

Fig. 1.-Typical tracing from the same human eye during the continuous infusion of 197 $\mu \mathrm{l}$. min. ${ }^{-1}$ saline before and after enucleation. The ocular rigidity was calculated from these records by determining in steps of $10 \mathrm{~mm}$. $\mathrm{Hg}$ the volume of saline infused. The blood pressure was $95 / 60 \mathrm{~mm}$. $\mathrm{Hg}$. 
The pressure curves observed on the enucleated eyes were found to increase in slope with an increase in pressure over the whole range of pressures studied.

- In contrast, the mean pressure curves on living eyes were found to be of a more complex nature; thus the slope of the curve increased over the range 20 to $50 \mathrm{~mm} . \mathrm{Hg}$, and then decreased continuously as the intra-ocular pressure approached more and more closely to the arterial blood pressure (see Fig. 1). A further change in slope was found as the intra-ocular pressure exceeded the blood pressure, at which point the slope began to increase again and became indistinguishable from that of the dead eye (see Fig. 2).
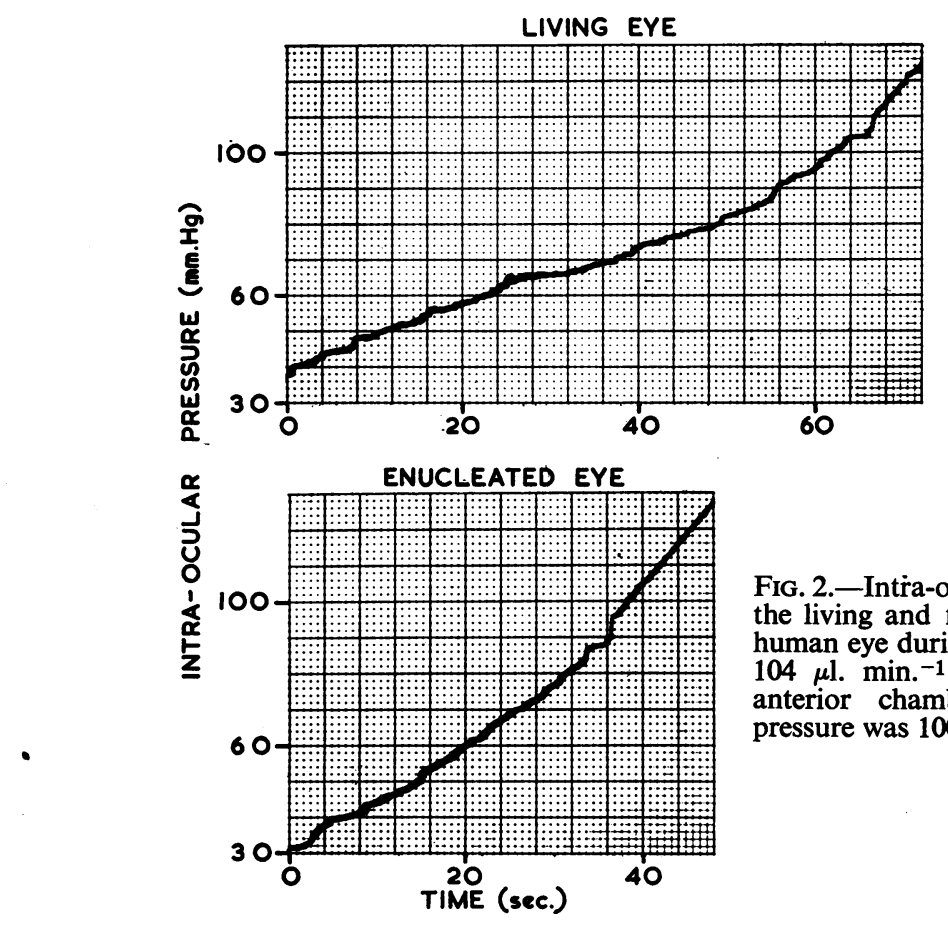

Fig. 2.-Intra-ocular pressure of the living and freshly enucleated human eye during the infusion of $104 \mu$ l. min. ${ }^{-1}$ saline into the anterior chamber. The blood pressure was $100 / 60 \mathrm{~mm}$. $\mathrm{Hg}$.

Analyses of the pressure and volume changes in the whole group of eyes studied in this way are summarized in Table III (opposite) and details of a typical calculation are recorded in Table IV (opposite). The coefficient of ocular rigidity was found to decrease with an increase in pressure in both the living and freshly enucleated eyes over the pressure range of 20 to 60 $\mathrm{mm}$. Hg. In all three subjects the rigidity of the enucleated eye at any pressure level was higher than that of the living eye.

Friedenwald (1937) analysed the experimental results of several previous investigators and concluded that the relationship between pressure and volume changes of the eye approximated to the equation $P_{1}=P_{0} e^{K \Delta V}$ where $P_{0}$ and $P_{1}$ were the initial and final pressures for a change of volume 
TABLE III

AVERAGE COEFFICIENT OF OCULAR RIGIDITY OF THE LIVING ANDENUCLEATED EYE OF THREE PATIENTS FOR A SERIES OF PRESSURE RANGES

\begin{tabular}{c|c|c|c|c|c}
\hline \multirow{2}{*}{ Patient No. } & \multirow{3}{*}{ Eye } & \multicolumn{3}{|c}{ Intra-ocular Pressure Range (mm. Hg) } \\
\cline { 2 - 6 } & & $23-33$ & $33-43$ & $43-53$ & $53-63$ \\
\hline 1 & Living & 0.0137 & 0.0102 & 0.0076 & 0.0064 \\
& Enucleated & 0.0184 & 0.0129 & 0.0140 & 0.0102 \\
\hline 2 & Living & 0.0149 & 0.0113 & 0.0079 & 0.0064 \\
& Enucleated & 0.0182 & 0.0140 & 0.0127 & 0.0124 \\
\hline 3 & Living & 0.0140 & 0.0112 & 0.0075 & 0.0076 \\
& Enucleated & 0.0119 & 0.0112 & 0.0106 & 0.0101 \\
\hline
\end{tabular}

TABLE IV

CALCULATION OF THE COEFFICIENT OF OCULAR RIGIDITY $(K)$ OF THE LIVING AND ENUCLEATED HUMAN EYE (PATIENT 2) BY THE CONTINUOUS TECHNIQUE The volume capacity of the system was $0.014 \mu \mathrm{l} . \mathrm{mm}$. $\mathrm{Hg}^{-1}$.

\begin{tabular}{|c|c|c|c|c|c|}
\hline \multirow{2}{*}{ Eye } & \multicolumn{5}{|c|}{ Results } \\
\hline & $\begin{array}{l}\text { Pressure Range } \\
\quad(\mathrm{mm} . \mathrm{Hg})\end{array}$ & $23 \cdot 0-33 \cdot 0$ & $33 \cdot 0-43 \cdot 0$ & $43 \cdot 0-53 \cdot 0$ & $53 \cdot 0-63 \cdot 0$ \\
\hline Living & $\begin{array}{c}\text { Total Volume } \\
\text { Outflow Volume } \\
\Delta V \\
K\end{array}$ & $\begin{array}{c}10 \cdot 86 \\
0 \cdot 18 \\
10 \cdot 54 \\
0 \cdot 0149\end{array}$ & $\begin{array}{c}10.53 \\
0.21 \\
10.18 \\
0.0113\end{array}$ & $\begin{array}{c}12.00 \\
0.40 \\
11.46 \\
0.0079\end{array}$ & $\begin{array}{c}12.67 \\
0.77 \\
11.76 \\
0.0064\end{array}$ \\
\hline Dead & $\begin{array}{c}\text { Total Volume } \\
\text { Outflow Volume } \\
\Delta V \\
K\end{array}$ & $\begin{array}{l}8 \cdot 82 \\
0 \cdot 08 \\
8 \cdot 60 \\
0 \cdot 0182\end{array}$ & $\begin{array}{l}8.42 \\
0.09 \\
8 \cdot 19 \\
0.0140\end{array}$ & $\begin{array}{l}7 \cdot 37 \\
0 \cdot 11 \\
7 \cdot 12 \\
0 \cdot 0127\end{array}$ & $\begin{array}{l}6 \cdot 32 \\
0 \cdot 13 \\
6 \cdot 05 \\
0 \cdot 0124\end{array}$ \\
\hline
\end{tabular}

$\Delta V$ and $K$ was the proportionality constant; thus he found that a graph of $\log P_{1}$ against $\Delta V$ was approximately linear. A more detailed examination of his figure for dead human eyes, however, reveals that the distribution of the calculated points was not symmetrical about the mean straight line. This is exactly what has been found in the present studies where the continuous nature of the observations brings out very clearly the change in slope of the curve (see Fig. 3, overleaf). It is this slow bending of the curve that causes $K$ the slope to decrease continuously over the pressure range of 20 to $70 \mathrm{~mm} . \mathrm{Hg}$ in the dead and living eyes.

The rapid injection of a given volume of saline into the eye produced records of which Fig. 4 (overleaf) is a typical example. Again the pressure response of the enucleated eye was greater than in the living eye when equivalent volumes of saline were infused. 


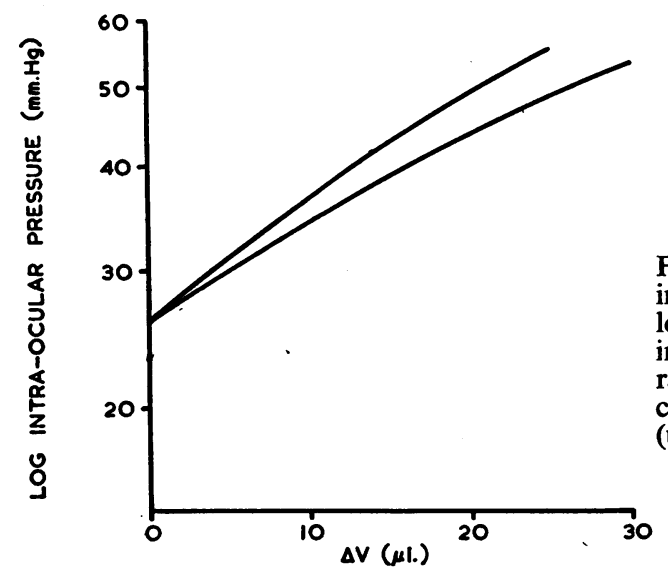

Fig. 3.-Mean relationship between the intra-ocular pressure (plotted on a logarithm scale) and the volume of fluid infused into the anterior chamber (at a rate of $197 \mu \mathrm{l}$. min.-1) of living (lower curve) and the freshly enucleated eyes (upper curve) of three patients.

LIVING EYE

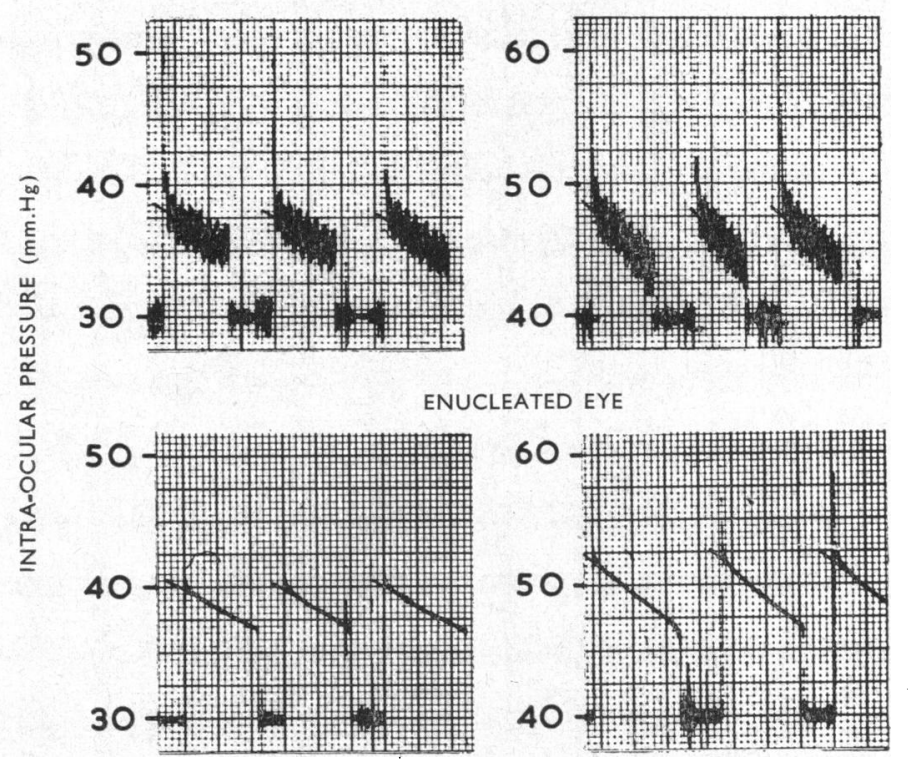

FIG. 4.-Typical record from the rapid infusion of $9.6 \mu \mathrm{l}$. saline into the human eye before and after enucleation. The pressure response of the enucleated eye is greater than that of the living eye at corresponding pressures. The overshoot characteristic of the rapid technique is ignored and the actual pressure change in the eye is found by extrapolating the slope of the pressure decay curve back of zero time.

The individual results of these measurements are recorded in Fig. 5 (opposite) and the mean values for the whole group of eyes are shown in Table V (opposite). There was a tendency for the ocular rigidity measurements made during descending pressure steps to be slightly higher than the values obtained during the ascending phase, particularly in the case of the enucleated eyes. However, no increase in ocular rigidity was seen when the 


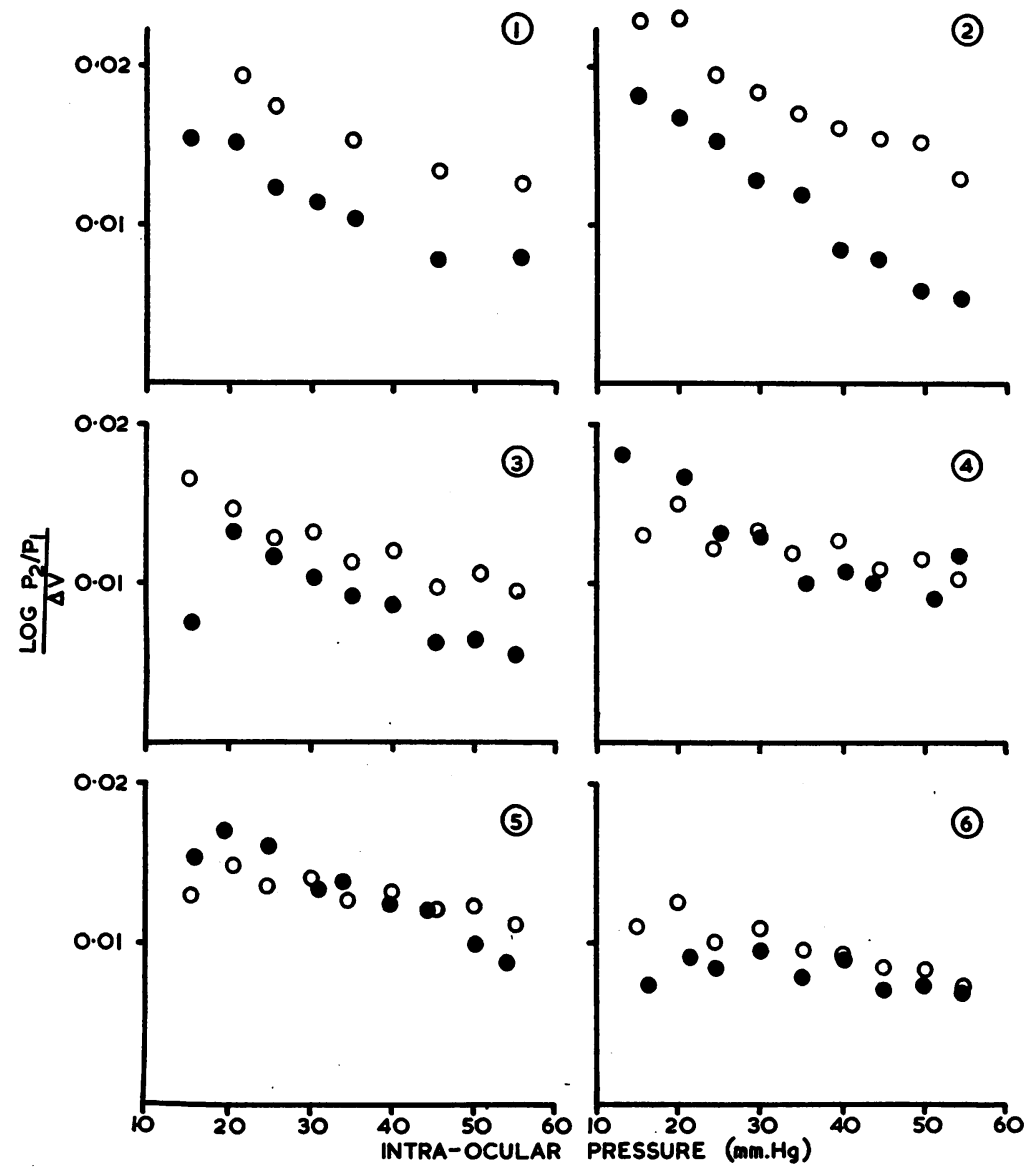

FIG. 5.-Coefficient of ocular rigidity of the living (O-O) and freshly enucleated $(O-O)$ eyes of individual patients studied by the rapid infusion technique.

TABLE V

COEFFICIENT OF SCLERAL RIGIDITY IN THE LIVING AND ENUCLEATED EYES OF THE SIX PATIENTS STUDIED BY THE RAPID INFUSION TECHNIQUE

\begin{tabular}{c|c|c}
\hline \multirow{2}{*}{ Initial Pressure (mm. Hg) } & \multicolumn{2}{|c}{ Eyes } \\
\cline { 2 - 3 } & Living & Enucleated \\
\hline 15.0 & $0.0136 \pm 0.0021(6)$ & $0.0152 \pm 0.0020(6)$ \\
20.0 & $0.0146 \pm 0.0013(6)$ & $0.0164 \pm 0.0016(6)$ \\
25.0 & $0.0128 \pm 0.0011(6)$ & $0.0142 \pm 0.0015(6)$ \\
30.0 & $0.0117 \pm 0.0006(6)$ & $0.0139 \pm 0.0013(5)$ \\
35.0 & $0.0104 \pm 0.0008(6)$ & $0.0128 \pm 0.0011(6)$ \\
40.0 & $0.0098 \pm 0.0007(5)$ & $0.0125 \pm 0.0012(5)$ \\
45.0 & $0.0083 \pm 0.0009(6)$ & $0.0115 \pm 0.0011(6)$ \\
50.0 & $0.0077 \pm 0.0009(5)$ & $0.0113 \pm 0.0011(5)$ \\
55.0 & $0.0076 \pm 0.0009(6)$ & $0.0106 \pm 0.0012(6)$ \\
\hline
\end{tabular}


infusion studies were repeated several times. In three out of the six subjects the rigidity at any pressure level was higher in the living eye, whereas in the three remaining eyes the differences were variable.

The results of the rapid and continuous methods are in close agreement; thus ocular rigidity decreased with increasing pressure and at different rates for the living and enucleated eye. Statistically, the difference between the living and dead eyes from this small group was found to be significant at the 5 per cent. level at $45 \mathrm{~mm}$. $\mathrm{Hg}$ and highly significant at pressures above $45 \mathrm{~mm}$. $\mathrm{Hg}$.

\section{Discussion}

It should be pointed out that none of the patients experienced any operative or post-operative complications. There was some discussion initially whether the elevation of the intra-ocular pressure to levels approaching 70 $\mathrm{mm}$. Hg would in any way increase the risk of metastatic spread of the tumour. In this regard it is interesting to note that, in the first eye studied, the intraocular pressure, monitored throughout the surgical procedure of enucleation, reached $200 \mathrm{~mm} . \mathrm{Hg}$ as the surgeon clamped the optic nerve. It seems unlikely that the comparatively modest pressure rise associated with the experimental procedure would increase the risk of tumour spread any more than the enucleation itself.

The results on enucleated eyes are in general agreement with recent studies in which the pressure-volume relationship of enucleated human eyes has been measured by a direct manometric technique. McBain (1958) observed a progressive decrease in the coefficient of ocular rigidity as the pressure increased from 5 to $94 \mathrm{~mm}$. $\mathrm{Hg}$, and proposed an alternative expression to relate pressure and volume changes of the eye,

$$
\text { namely that } \quad E=\frac{P_{2}^{0.35}-P_{1}^{0.35}}{\Delta V} \text {. }
$$

Application of this expression to the present results is shown in Fig. 6, and it will be seen that, while there is good agreement with McBain for freshly enucleated eyes, the pressure-volume relationship of the living eye could not be described in this manner.

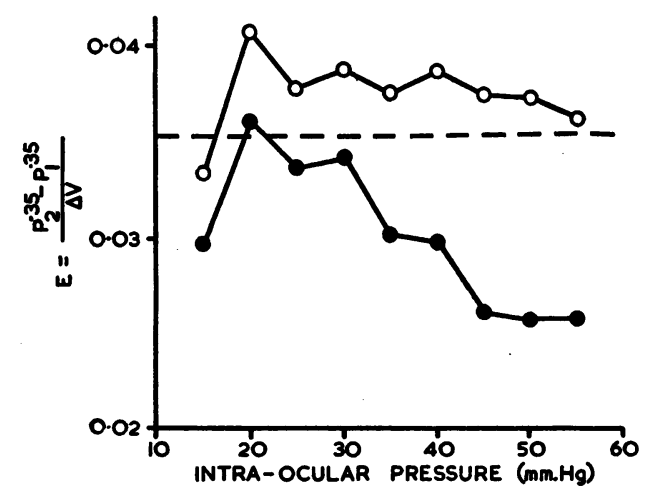

Fig. 6.-Pressure-volume relationship of living (O-O) and enucleated human eyes $(\mathrm{O}-\mathrm{O})$ calculated according to the formula proposed by McBain (1958). 
In similar studies on enucleated human eyes, Prijot (1958) noted a decrease in the coefficient of ocular rigidity of approximately 30 per cent. when the intra-ocular pressure was increased from 15 to $55 \mathrm{~mm}$. $\mathrm{Hg}$. Gloster and Perkins (1959) also found the coefficient of ocular rigidity of human eyes to decrease with pressure, and the studies of Macri, Wanko, and Grimes (1958) indicated a similar response although this was less consistent in individual eyes. On the other hand, Grant and Trotter (1955), in manometric determinations of the ocular rigidity of enucleated eyes, reported no change in the value of the coefficient in individual eyes when the pressure was changed from 10 to $45 \mathrm{~mm}$. $\mathrm{Hg}$. Unfortunately, they do not state how many eyes were examined in this way and it is therefore not possible to conclude whether their results differ significantly from the present ones. Thus, while in this study $K$ was found to decrease with pressure in all eyes, the change was only 22 per cent. over the pressure range of 20 to $40 \mathrm{~mm}$. $\mathrm{Hg}$.

The results of the manometric studies on living eyes show that the coefficient of ocular rigidity for an individual eye varies with pressure and at physiologic pressures has a value lower than the generally accepted value of 0.0215 . Similar conclusions were reported by Ytteborg (1960b) on the basis of manometric and tonometric determinations of ocular rigidity in twelve subjects. He found the coefficient of ocular rigidity to decrease from a mean value of 0.013 at $15 \mathrm{~mm}$. $\mathrm{Hg}$ to 0.0082 at $60 \mathrm{~mm}$. Hg. On the other hand, Prijot and Weekers (1959) made manometric determinations of ocular rigidity in two eyes that were to be removed because of tumour and concluded that the values were independent of pressure. However, examination of their results (Fig. 4 of their paper) shows that the values in one eye are completely consistent with the results and conclusions reported in this study. In the second eye examined by these investigators, the ocular rigidity varied greatly at different pressures and the effect of pressure is not discernible. It is of interest that they also found the coefficient of ocular rigidity to be significantly below 0.0215 in these eyes.

The same problem has been tackled by alternative techniques by several investigators. Moses and Tarkkanen (1959) recorded the pressure change in normal and pathological eyes for different areas of applanation usingapplanation tonometry, and concluded that the semilogarithmic plot of pressure and the volume of corneal indentation was approximately linear and appeared to confirm Friedenwald's formulation. However, in at least five of the eyes examined (see Fig. 2 of their paper), the results lay along a convex curve a fact which is consistent with the conclusions of this study that ocular rigidity decreases as intra-ocular pressure increases. In other tonometric studies, Draeger (1959) calculated the coefficient of ocular rigidity in 72 eyes from applanation and Schiötz tonometry and concluded that there was no variation with pressure; whereas, in a similar study on 560 patients, Goodside (1959) concluded that the coefficient of ocular rigidity decreased as the pressure of the eye rose. 
The difference in the reaction of the living and enucleated eyes of individual subjects to an injection of fluid is consistent with the hypothesis that a change in pressure causes a change in blood volume in the living eye. This explanation is supported by the observation that the discrepancy between the living and dead eye increased as the intra-ocular pressure approached the general blood pressure but then disappeared when the general blood pressure was exceeded. This finding is analogous to the results of similar experiments performed on rabbits (Eisenlohr and Langham, 1962) where a significant difference between the ocular rigidity of the living and dead eye was found in each of the animals studied. Furthermore, this difference could be abolished at any pressure level by reducing the blood pressure to a level below that of the intra-ocular pressure. In the same study, the inequality between the volume of fluid entering the eye and the volume change of the eye was most graphically demonstrative when the intra-ocular pressure and the mean blood pressure were nearly the same. At this point, the infusion of 197 $\mu 1$. min. ${ }^{-1}$ into the anterior chamber of the living rabbit eyes caused little if any pressure change and consequently blood must have left the eye almost as fast as the fluid entered.

On the assumption that the difference in ocular rigidity of the living and dead eye is due to vascular changes it is possible to calculate its magnitude from the difference in the value of the coefficient of ocular rigidity of the living and dead eye at any given pressure; the results of this calculation (shown in Table VI) indicate that the volume change is small for pressures below 50 $\mathrm{mm}$. $\mathrm{Hg}$ and, in this pressure range, is only a very small fraction of the total ocular blood volume of 200 to $300 \mu 1$. (Ridley, 1930). On the other hand, these calculations may be criticised on the basis that the perfusions of the dead eyes were not made with the eyes in situ. This aspect has been studied in rabbit eyes by comparing the results of perfusion experiments on dead eyes before and after enucleation and it was found that ocular rigidity was

TABLE VI

CHANGE IN BLOOD VOLUME OF INDIVIDUAL EYES FOR VARIATIONS IN THE INTRA-OCULAR PRESSURE

The results have been calculated from the volumes needed to increase the intra-ocular pressure by $10 \mathrm{~mm} . \mathrm{Hg}$ in living and enucleated eyes.

\begin{tabular}{c|c|c|c|c}
\hline \multirow{2}{*}{ Patient No. } & \multicolumn{4}{|c}{ Intra-ocular Pressure Range (mm. Hg) } \\
\cline { 2 - 5 } & $25-35$ & $35-45$ & $45-55$ & $55-65$ \\
\hline 1 & 3.29 & $3 \cdot 51$ & 4.91 & $3 \cdot 26$ \\
2 & 1.95 & $2 \cdot 71$ & $5 \cdot 87$ & $8 \cdot 10$ \\
3 & 1.24 & $2 \cdot 73$ & $5 \cdot 31$ & $5 \cdot 25$ \\
4 & 1.04 & 1.59 & 0.55 & 0.67 \\
5 & 1.57 & 0.79 & 0.0 & 1.63 \\
6 & 2.92 & $2 \cdot 78$ & 1.63 & 0.49 \\
\hline
\end{tabular}


somewhat higher in the enucleated eye (unpublished experiments). Consequently, if this is also true for human eyes, the vascular changes are even smaller than the above calculations indicate.

These conclusions do not agree either in kind or in magnitude with those recently reported by Ytteborg (1960a), who noted in manometric studies on human eyes that, when a tonometer was taken off the living eye, the intraocular pressure fell rapidly below its equilibrium level and then bounced back to normal, but that this response was not found in enucleated eyes. He suggested that the rebound phenomenon was due to blood refilling the eye and calculated the volumetric effect from the extent of the pressure change associated with the rebound. The calculated volumes were found to decrease with increase in pressure and to be much greater in magnitude than those reported in this paper. The validity of his interpretation must be seriously questioned, for the manometric recording system used by Ytteborg was filled with saline and it is known that sudden volumetric displacements will themselves cause a pressure overshoot unless damped by use of viscous fluid in the recording system (see Eisenlohr and Langham, 1962).

The practical significance of the present findings to the measurement of the outflow facility by tonography may be assessed from a consideration of a tonogram of one of the patients used in this study. In the eye the total volume increment of aqueous humour leaving the eye when the intra-ocular pressure decreases from a pressure $P_{t 1}$ at time $t_{1}$ to a pressure $P_{t 2}$ at time $t_{2}$ during tonography is given by the sum of three terms, namely,

$$
\Delta V=\left(\frac{1}{K} \log \frac{P t_{1}}{P t_{2}}\right)+\left(V c_{2}-V c_{1}\right)+\left(V_{B 2}-B_{B 1}\right) .
$$

The first term is Friedenwald's pressure-volume relationship of the dead eye, the second term represents the change in the volume of corneal indentation due to application of the tonometer, and the third term represents the change in blood volume of the eye. From an analysis of the tonogram recorded on the first patient the change in volume of the aqueous humour was given by $(4 \cdot 2+9 \cdot 0+2 \cdot 0) \mu 1$, where the three values correspond in order to the terms in the above expression. It is evident from this calculation that $\Delta V$ is determined principally by the change in the volume of corneal indentation, whereas the vascular change accounts for only 13 per cent. of the total. Correction of the first term for the observed alteration of $K$ with pressure altered $\Delta V$ less than 5 per cent. With $\Delta V$ known, the outflow facility is expressed as the rate of loss of this volume per unit of increased pressure gradient. Using the conventional method for the analysis of tonograms, the outflow facility of this eye was $0.29 \mu 1 . \mathrm{min} .^{-1} \mathrm{~mm}$. $\mathrm{Hg}^{-1}$; this increased to a value of $0.40 \mu 1$. min. $^{-1} \mathrm{~mm}$. $\mathrm{Hg}^{-1}$ when Friedenwald's $K$ of 0.0215 was replaced by the value of 0.0104 which had been determined experimentally on this eye and increased to a value of $0.44 \mu 1 . \mathrm{min}^{-1} \mathrm{~mm}$. $\mathrm{Hg}^{-1}$ when correction was made for the change in blood volume during tonography. Thus the 
total correction was 52 per cent. and this was typical of the results on the group of patients. Recognition of these sources of error in tonography is of importance both for the evaluation of the accuracy of this technique and for improving the means of differentiating between normal and glaucomatous eyes.

\section{Summary}

(1) The relationship between pressure and volume changes in six human eyes has been studied both before and immediately after enucleation. The observations were made by recording manometrically the intra-ocular pressure either to a sudden injection of a predetermined volume of saline or to a continuous infusion of saline.

(2) A continuous infusion of $197 \mu \mathrm{l} . \mathrm{min} .^{-1}$ of saline was found to give a different pressure response in the living and dead eye. In the dead eye the slope of the curve increased continuously, whereas in the living eye the slope increased to approximately $60 \mathrm{~mm} . \mathrm{Hg}$ and then reversed until the intraocular pressure exceeded the mean blood pressure, at which level the slope began to increase again. Reasons are given for associating these changes with loss of blood from the eye.

(3) Calculations of the coefficient of ocular rigidity for $5 \mathrm{~mm}$. $\mathrm{Hg}$ pressure steps over the pressure range of 20 to $65 \mathrm{~mm}$. $\mathrm{Hg}$ were made from the results of the two techniques and the values were essentially the same. Furthermore, they confirmed the conclusions of recent investigators that the - coefficient decreases in value with an increased pressure in the eye.

(4) In individual eyes the coefficient of ocular rigidity was significantly greater in the enucleated than in the living eye at corresponding pressures in three out of the six eyes studied. In the remaining three eyes the difference was either small or insignificant.

(5) The significance of these results is discussed in relation to recent investigations and to tonographic analysis.

\section{REFERENCES}

Draeger, J. (1959). Docum. ophthal. (Den Haag), 13, 431.

EISENLOHR, J., and LANGHAM, M. E. (1962). Invest. Ophthal., 1, 63.

FriedenWALD, J. S. (1937). Amer. J. Ophthal., 20, 985.

Gloster, J., and Perkins, E. S. (1959). Brit. J. Ophthal., 43, 97.

Goodside, V. (1959). A.M.A. Arch. Ophthal., 62, 839.

Grant, W. M., and TrotTer, R. R. (1955). Ibid., 53, 191.

LANGHAM, M. E. (1959). Brit. J. Ophthal., 43, 705.

MACRI, F. J., WANKo, T., and Grimes, P. A. (1958). A.M.A. Arch. Ophthal., 60, 1021.

McBaIn, E. H. (1958). Ibid., 60, 1080.

Moses, R. A., and BeCKer, B. (1958). Amer. J. Ophthal., 45, 196.

and TARKKANEN, A. (1959). Ibid., 47, No. 1, Pt 2, p. 557.

PriJot, E. (1958). Acta ophthal. (Kbh.), 36, 865.

Prot, and WEEKERS, R. (1959). Ophthalmologica (Basel), 138, 1.

Ridley, F. (1930). Brit. J. exp. Path., 11, 217.

YTTEBORG, J. (1960a). Acta ophthal. (Kbh.), 38, 410.

(1960b). Ibid., 38, 548. 